\title{
EL ARGUMENTO CONTRA LA SUERTE MORAL: ARTICULACIÓN Y RESPUESTA
}

\author{
SERGi RoselL \\ Philosophy Department \\ University of Sheffield \\ s.rosell@sheffield.ac.uk
}

RESUMEN: En la primera parte del artículo se reconstruye detalladamente el argumento global contra la suerte moral en todos sus tipos, distinguiendo dos estrategias principales (moderada y radical). A continuación se defiende que ninguna de ellas es sostenible, pues si la primera resulta insuficiente, la segunda es impráctica y finalmente incoherente. Fundamentalmente se intenta mostrar que un argumento definitivo contra la suerte moral en todos sus tipos dependerá por necesidad de la noción imposible de merecimiento incondicionado, o merecimiento verdadero (esencial), en el sentido especialmente fuerte de función estricta del control del agente (o estrictamente proporcional a dicho control).

PALABRAS CLAVE: merecimiento verdadero, responsabilidad moral, control, culpabilidad, historias contrafácticas

SUMMARY: After a detailed reconstruction of the global case against moral luck in all its kinds, which distinguishes two main argumentative strategies, the moderate strategy and the radical strategy; a twofold counter-argument is presented. It is argued that (i) whereas the former turns out to be insufficient, (ii) the latter becomes impractical and eventually incoherent. The fundamental aim is to show that a final argument against moral luck necessarily depends on the impossible notion of unconditional desert — or true desert understood, in a especially strong sense, as the strict function of (or strictly proportional to) the agent's control.

KEY WORDS: true desert, moral responsibility, control, blame, counterfactual histories

Una nada presta el mismo servicio que un algo sobre el que nada puede decirse.

L. Wittgenstein $(I F, \S 304)$

Los objetivos de este artículo son dos. Por un lado, aspiro a reconstruir detalladamente, y de la manera más convincente posible, el argumento contra la suerte moral. Por el otro, trataré de mostrar que el argumento falla y dónde o por qué falla. El argumento, que llamaré argumento global contra la suerte moral, o simplemente argumento global, es ambicioso, pues trata de rechazar la existencia de la suerte moral en todos sus tipos. En mi reconstrucción del argumento distinguiré dos estrategias principales, una moderada y la 
otra radical, que pasaré a atacar individualmente. Si mi réplica es convincente, resultará que la primera es insuficiente, y la otra, por completo impráctica y, a fin de cuentas, incoherente. En todo caso, mi réplica, como reducción al absurdo del argumento evaluado, no se traducirá en la defensa positiva de tipos particulares de suerte moral, pero sí que nos llevará a concluir que es inevitable que la suerte influya en nuestra agencia moral y en los consiguientes juicios de responsabilidad moral que merecemos. En general, me sitúo del lado de los defensores de la suerte moral y trato de replicar a los argumentos más recientes en su contra.

\section{La suerte moral y sus tipos}

El fenómeno de la suerte moral, si es posible, se dará cuando un agente pueda ser juzgado - esto es, tratado como objeto de juicio moral-, de manera correcta, con independencia del hecho de que un aspecto significativo de aquello por lo que este agente es evaluado dependa de factores que escapan a su control. ${ }^{1}$ En general, lo que se discute son ejemplos en los que los juicios morales que los agentes reciben están mediatizados por elementos que escapan a su control; nos enfrentaríamos entonces a la tensión que surge entre el hecho de que parece que la suerte no puede afectar a la responsabilidad o censura moral y la posibilidad real de que desempeñe un papel importante, o incluso crucial. La discusión gira en torno a la siguiente pregunta: ¿puede la suerte llegar a marcar una distinción moral?

Hay que tener en cuenta, además, que el fenómeno puede plantearse de maneras significativamente distintas, por lo que cabe distinguir entre diversos tipos de suerte moral: ésta podría deberse a cómo resultan las cosas tras la decisión y acción del agente - esto es, a los diferentes resultados - ; a las circunstancias particulares en que el agente se ve inmerso y tiene que actuar; a las circunstancias en las que desarrolló su carácter moral, principios o valores, que lo llevaron a actuar de uno u otro modo; o incluso al temperamento e inclinaciones innatas o iniciales, que pueden hacer de alguien una persona más o menos predispuesta a responder adecuadamente a las exigencias morales. Me referiré a estos tipos, respectivamente, como suerte moral resultante, circunstancial, formativa y constitutiva. Además, para simplificar, en ocasiones agruparé los dos últimos tipos usando la expresión de suerte moral antecedente. ${ }^{2}$

\footnotetext{
${ }^{1}$ Véanse Nagel 1979, p. 26, y Williams 1981, p. 30.

${ }^{2}$ Para una caracterización más detenida del fenómeno en la que se contrastan los
} 
Esbozado el fenómeno y sus tipos posibles, paso a reconstruir el argumento global contra la suerte moral, a partir de los diferentes argumentos presentes en la bibliografía. De hecho, creo que puede reconstruirse un argumento fundamental — desplegado de forma más o menos independiente por diversos filósofos-, a partir del cual se desprenden diferentes variaciones. A continuación, defenderé que es imposible que un argumento de este tipo pueda finalmente prevalecer. Mi razón es que habría de depender de una noción tan misteriosa como la de merecimiento incondicionado, o merecimiento verdadero entendido en el sentido especialmente fuerte - que muchos atribuyen a Kant - de función estricta del control del agente (o estrictamente proporcional a dicho control); noción que, llevada a sus últimas consecuencias, resultará ser incoherente, además de totalmente impráctica.

\section{El argumento contra la suerte moral}

Los negadores de la suerte moral abogan por la defensa del principio de control, según el cual un agente es moralmente responsable sólo de aquello que cae bajo su control y en el grado proporcional a su control. Aferrándose a este principio, tratan de mostrar que el supuesto fenómeno de la suerte moral, tras la debida reflexión, resulta ser una ilusión.

Un arma fundamental para alcanzar esta conclusión es el argumento epistémico (AE), según el cual los supuestos casos de suerte moral no muestran que la suerte pueda afectar realmente el juicio moral que una persona merece, su estatus moral, sino que sólo afectan nuestro conocimiento de lo que ella merece, pues no en balde no somos seres omniscientes y nuestro conocimiento está ligado a la evidencia a la que tenemos acceso. ${ }^{3}$

(AE) Lo que la suerte realmente hace no es interferir en el estatus moral de alguien, sino en el conocimiento que tenemos

planteamientos de Nagel y de Williams, se analizan y reclasifican los diferentes tipos de suerte moral y se exponen las principales estrategias posibles de resolución del "problema", véase Rosell 2006.

${ }^{3}$ El nombre se debe a Latus 2000. Para este tipo de argumento, véanse Jensen 1984, Richards 1986, Thomson 1989, Rescher 1990, Rosebury 1995, Latus 2001, y Enoch y Marmor 2007; también Zimmerman 1987 y 2002, aunque su posición es singular, como veremos. 
de éste, dado que no somos seres omniscientes y nuestro conocimiento depende de la evidencia disponible. ${ }^{4}$

Empecemos viendo cómo funciona este argumento en relación con un (supuesto) caso de suerte moral en las consecuencias. José y Josué son dos amigos que tras estar bebiendo unas cervezas en un bar deciden volver a casa conduciendo cada uno su auto. En el camino de vuelta, José atropella a un hombre, no así Josué. Parece que cotidianamente tendemos a juzgar con más severidad - lo que prima facie indicaría que lo consideramos más culpable - a José, el conductor que atropella y causa un daño a alguien, que a Josué, que no atropella a nadie. Esto supondría que la suerte marca una distinción moralmente relevante $\mathrm{y}$, de ahí la presencia de la suerte moral. De hecho, en el primer caso tenemos un atropello, y con ello una persona que sufre un daño importante, mientras que en el segundo caso no hay atropello y nadie sale mal parado. Sin embargo, el negador de la suerte moral puede reconocer que, desde luego, la suerte interviene en el caso, pues uno de ellos atropella a alguien y el otro no. José produce un daño que Josué no produce. Hay, pues, un sentido en el que la suerte interviene en nuestro juicio moral, es decir, hay un sentido en el que José parece ser menos afortunado que Josué en relación con el juicio que merece. Pero ello no implica que la suerte marque realmente una diferencia moral, esto es, que afecte lo que la persona verdaderamente o a fin de cuentas merece. En realidad, continúa el argumento, ambos conductores son igualmente culpables, si la temeridad de ambos es la misma, con independencia de las consecuencias de sus acciones.

En condiciones normales sólo sabemos que Josué no ha causado ningún daño, lo cual no es motivo para sospechar de su falta de rectitud al volante. Seguramente, Josué suele conducir prestando atención a la carretera, yendo a una velocidad segura, etc. O quizá no. Pero no hay nada que nos haga desconfiar o sospechar, o incluso preguntarnos, si es o no así. Sin embargo, José ha atropellado a alguien, y esto nos hace pensar que posiblemente su atención no

\footnotetext{
${ }^{4}$ Esta tesis aúna lo que tienen en común los siguientes pasajes: "El culpable puede así ser afortunado o desafortunado en la claridad de su merecimiento" (Richards 1986, p. 169). "La suerte implicada no tiene que ver con nuestra condición moral, sino sólo con nuestra imagen; está conectada no a lo que somos sino a cómo nos ve la gente (incluso nosotros mismos)" (Rescher 1990, pp. 154-155). "Si el daño real se da, el agente y otros que consideran su acto tendrán un dolorosa conciencia de este daño" (Jensen 1984, p. 136). "El daño real sólo tiene la función de hacer vívido cuán mala fue la acción debido al peligro creado" (Bennett 1995, pp. 59-60).
} 
era la adecuada, o que su velocidad era excesiva, etc.; en definitiva, que fue temerario, y que no sopesó correctamente el riesgo que su conducción temeraria comportaba a otros usuarios de aquella vía pública. Si esto es así, el negador de la suerte moral puede conceder sin excesivos problemas que la suerte puede influir incluso en el juicio moral que ordinariamente emitimos, pero ello no repercute en el estatus moral del agente. Ésta es, en especial, la posición de Norvin Richards, quien defiende explícitamente que, cuando no existe un daño real, la cuestión permanece incierta, y que precisamente cuando la suerte abandona a alguien tenemos la base suficiente como para tratarlo de la manera en la que hubiese merecido ser tratado desde el principio. 5

En todo caso, lo que cabe retener, según los defensores de AE, es que una persona podrá ser afortunada o desafortunada en la claridad de lo que merece, pero ello no significa que la suerte pueda marcar una distinción moral, es decir, afectar lo que merece, su merecimiento (verdadero). ${ }^{6}$

Con esto, podríamos tratar ya de desenmascarar el error de las caracterizaciones típicas de los supuestos casos de suerte moral, reteniendo, al mismo tiempo, el principio de control y nuestras prácticas cotidianas de juicio. Aunque ello depende del compromiso adicional - que va más allá del núcleo estricto de $\mathrm{AE}$ - con una distinción fundamental entre los juicios que estamos justificados a proferir, dada la limitación de nuestras facultades cognitivas y la evidencia accesible, y aquello que la persona realmente merece, su merecimiento real. ${ }^{7}$ Llamaré a este compromiso adicional la tesis conservadora (por antirrevisionista).

${ }^{5}$ Richards 1986, p. 171. Esta última idea me parece discutible, pero no es mi propósito discutirla aquí. Mi meta inmediata es evaluar si AE puede extenderse adecuadamente a todas las formas de suerte moral o no.

${ }^{6}$ Utilizo "merecimiento" como traducción de desert, que en la bibliografía especializada (en inglés) se prefiere a merit, para el cual es más fácil reservar el castellano "mérito". En principio, la diferencia principal sería que desert se usa normalmente para hablar de las acciones de alguien, y merit hace más bien referencia a sus capacidades y habilidades, en el sentido de hechos sobre alguien. En el primer caso se trataría de algo por lo que el sujeto es (más genuinamente) responsable, mientras que no lo es (tan claramente) por lo segundo. Merecimiento y mérito evocarían respuestas diferentes: te admiro por tus méritos, te elogio en la medida de tu merecimiento. Cfr. Lucas 1993, pp. 124-127. Sin embargo, es esta distinción, que sólo ambiguamente se reconoce en el discurso ordinario y admite diferentes grados de rigidez, lo que la hace inestable en el nivel teórico. De hecho, la misma falta de nitidez de esta distinción será parte de la discusión.

${ }^{7}$ Es la posición de Richards 1986, Rosebury 1995 y Thomson 1989. 
Así, nuestro trato diferencial a José y Josué dependería no del hecho de que realmente merezcan un trato diferente, sino de que, en primer lugar, su conducta no nos muestra con la misma claridad que lo que merecen sea lo mismo y, en segundo lugar, nuestro trato debe reflejar nuestra comprensión (epistémicamente limitada) de lo que merecen, y por lo tanto cómo tenemos el deber de tratarlos. ${ }^{8}$ En otras palabras, por un lado, no siempre quedan claros cuáles son las intenciones de una persona, su compromiso con un curso de acción, su verdadera voluntad, etc. Y, por otro, como humanos, no tenemos acceso a una perspectiva omnisciente que nos permita conocer exactamente el merecimiento de uno y otro. Así, el resultado de sus respectivas acciones parece ser el mejor indicador que tenemos para saber cómo debemos tratarlos.

Sin embargo, también puede apelarse a una estrategia ligeramente distinta, que en vez de incidir en la falibilidad del juicio humano, lo hace en los diferentes propósitos que cotidianamente guían nuestras prácticas de evaluación moral; a saber, cotidianamente censuramos a aquellos que causan sucesos negativos con la pretensión de cambiar su conducta, con independencia de si realmente merecen ser censurados. En otras palabras, una cosa serían los actos de censura, consistentes en someter a alguien a censura explícita, pública, típica de los reproches, las reprimendas, etc., y otra los juicios de culpabilidad moral, en los que la intención primaria del hablante es dar un veredicto impersonal aplicable a todos aquellos cuyas acciones son iguales en los aspectos relevantes, con el propósito de juzgarlos como merecedores de censura moral y no con el de meramente influir en su conducta. Ambos constituirían, además, tipos distintos de aseveración. ${ }^{9}$

$\mathrm{Si}$, de nuevo, aplicamos esta distinción al caso de los conductores temerarios, cabría decir que sólo al conductor que atropella a un peatón se le puede censurar abiertamente — no así al conductor que no atropella a nadie (y en relación con el no atropello)—, aunque

${ }^{8}$ Véase Richards 1986, pp. 171-172.

${ }^{9}$ Véase Thomson 1989, pp. 200-203, y Jensen 1984, pp. 132-134, para defensas destacadas de esta posición. En la misma línea, Zimmerman (1987, pp. 218-219) distingue entre elogio y censura activos e inactivos. Cabe subrayar que, para algunos teóricos, la noción de censura aparece como más urgente que la de elogio, lo que apuntaría a una asimetría entre ambas. Parece claro, al menos, que la censura es un fenómeno más complejo que el elogio, por lo que merecería una atención más detenida - pues la censura improcedente parece producir mayor injusticia que el elogio improcedente - Véase Wolf 1990, para una defensa destacada de la asimetría entre elogio y censura, aunque por razones distintas. 
ambos sean igualmente culpables. José es censurable por producir un daño moral, dado que causó el atropello (sin tener una excusa adecuada). No así Josué, que no atropelló a nadie. Sin embargo, esto no marca una distinción en su calidad como personas; ambos son igualmente buenas o malas personas (y deberían producirnos la misma indignación moral). ${ }^{10}$ Con ello, la suerte (en las consecuencias, en este caso) sólo puede marcar una distinción moral en la censura explícita, pero no en la culpabilidad y calidad como persona de los agentes, que es precisamente la esfera evaluativa fundamental que permanece inmune a la suerte.

Alternativamente, otro movimiento, mucho más vasto - pero que muestra de modo bastante más intuitivo la meta de la estrategia que estamos considerando- es denunciar que en los supuestos casos de suerte moral a menudo se confunde suerte moral con suerte legal. La idea es que si bien podemos tener buenas razones legales para tratar a uno y a otro de manera diferente - esto es, castigar más severamente a José que a Josué-, es un error inferir de aquí que la ley refleje directamente la evaluación moral correcta de tales casos. Ciertamente, el derecho constituye un sistema que gobierna la atribución de responsabilidad y la respuesta punitiva, entre cuyos objetivos centrales está contribuir al bienestar social impidiendo la comisión de actos criminales. Para ello establece un conjunto de convenciones, incluyendo la pena legal, que priva al criminal y trata de disuadir. De este modo, los juicios legales no pueden ser regulados por una concepción de la responsabilidad moral independiente de la suerte, dado su carácter intrínsecamente convencional. ${ }^{11}$ No obstante, de esto sólo se sigue que no todo caso de suerte legal constituye, eo ipso, un caso de suerte moral. Pero no que por ser casos de suerte legal ya no puedan serlo de suerte moral. Aparte de las razones legales que justifican castigar más severamente el crimen efectivo que el mero intento, también pueden existir razones morales para ello. De hecho, no son pocos los juristas y teóricos del derecho que consideran que el derecho ha de mantener una estrecha correspondencia con la moralidad; como no es inusual que se produzca un fuerte rechazo popular cuando los tribunales dictan sentencias que claramente chocan con la moralidad. Si, por lo menos, la legalidad rastrea la moralidad, podría

${ }^{10}$ Veáse Thomson 1989.

${ }^{11}$ Para el desarrollo de este argumento, véase Rosebury 1995, pp. 521-524. Ya Nagel hacía notar que una objeción probable a su caso de los asesinos efectivo y frustrado sería que hacer más responsable a uno que a otro "se asemeja a la responsabilidad objetiva (strict liability), que puede tener sus usos legales pero parece irracional como posición moral" (1979, p. 31). 
haber casos de suerte legal y moral a la vez. Así, el hecho de que un caso determinado cuente como caso de suerte legal no impide que pueda ser, a su vez, un caso de suerte moral, aunque tampoco implica que lo sea. ${ }^{12}$

Es importante darse cuenta de que estas distinciones son, sin duda, compatibles. Podríamos empezar distinguiendo entre juicios morales y juicios legales; luego, distinguir, dentro de los juicios morales, entre juicios de culpabilidad moral y actos de censura; y entre el juicio que el agente merecería y el que estamos justificados a emitir dada nuestra inescapable limitación epistémica. Por otro lado, cabe diferenciar entre el propio AE y las diferentes implementaciones de la tesis conservadora. El núcleo de $\mathrm{AE}$ es esencialmente negativo, dice lo que no es; mientras que la tesis conservadora (que, recordemos, justifica el trato diferente de uno y otro agente en virtud de las claras diferencias en las consecuencias de su conducta - así como en la diferente conducta, como veremos-, aunque sólo sea en relación con la censura explícita, o el mero juicio legal) constituye un determinado desarrollo positivo, entre los posibles, que va más allá del núcleo de AE. El defensor de AE no tiene, estrictamente, por qué comprometerse con ninguna explicación positiva particular de nuestras prácticas, aunque ofrecer una buena explicación favorece enormemente su posición.

Hasta ahora sólo hemos considerado cómo responde el negador de la suerte moral a los casos de suerte resultante. Para conseguir un argumento global contra la suerte moral es necesario que éste se pueda aplicar convenientemente a todos los tipos de suerte moral. Sin embargo, no está claro de qué modo este tipo de explicación - que tiene su banco de pruebas principal en la suerte en las consecuencias - puede extenderse sin más a la suerte circunstancial, formativa y constitutiva. La solución quizá venga de la mano de la sofisticación de las distinciones anteriores, aunque también puede suceder que su adecuada extensión resulte difícil o imposible. No niego que las distinciones aludidas, y otras que se propondrán, no hagan parcialmente justicia a nuestra comprensión de los juicios de responsabilidad moral. Además, algunas aprovechan oposiciones clásicas, como el elogio y la censura fruto del merecimiento, o como

\footnotetext{
${ }^{12}$ La misma posibilidad de que la suerte (principalmente resultante) deba marcar una diferencia en la atribución de responsabilidad legal — especialmente en derecho penal, pero también en derecho civil - es objeto de controversia. La bibliografía al respecto es rica y extensa; véanse, en particular, Hart 1968, Davis 1986, Sverdlik 1988, Lewis 1989, Moore 1994, Feinberg 1995, o Levy 2005. Para más referencias, consúltese la bibliografía en este último artículo.
} 
medios para conseguir consecuencias deseadas - influir en la conducta del agente, para reeducarlo, disuadirlo, etc.- - Sin embargo, como veremos, se requiere algo más para negar la existencia de la suerte moral.

\section{Escenarios contrafácticos}

La idea que permite generalizar la posición anterior a todos los tipos de suerte moral viene de la mano de la formulación contrafáctica del principio de control: el merecimiento moral de una persona - lo que ésta verdaderamente merece - no será resultado de lo que haya hecho, sino de lo que habría hecho si hubiera tenido la ocasión. ${ }^{13}$

Considérese el caso más clásico de suerte circunstancial: el de los dos simpatizantes nazis. ${ }^{14}$ Rudolf y Adolf son adeptos, en la misma medida, a la política que el nazismo está empezando a desplegar en Alemania y Austria, pero Adolf ha tenido que emigrar a Argentina por cuestiones de negocios y no puede participar activamente en ella. Rudolf, por el contrario, permanece en Alemania, y tiene la opción de enrolarse en las SS y acabar comandando un campo de exterminio. Según el defensor de la suerte moral circunstancial, las diferentes circunstancias de ambos les abren y cierran diferentes oportunidades de acción que pueden acabar marcando una diferencia moral en sus respectivos merecimientos. Parece claro que, en principio, el juicio que Rudolf nos merece (miembro de las SS y comandante de un campo de exterminio) es mucho más adverso que el juicio de Adolf (mero simpatizante en la lejanía). Sin embargo, el negador de la suerte moral afirma que lo realmente relevante no es cómo cada uno de ellos finalmente actuó, sino que si hubiera estado en las mismas circunstancias que Rudolf, Adolf habría actuado libremente del mismo modo, esto es, se habría integrado en el nazismo en la misma medida y habría cometido los mismos horrendos crímenes. Siendo esto así, ambos son igualmente responsables.

Si bien, por otro lado, la tesis conservadora nos permite tratar más duramente a Rudolf que a Adolf. Dados los hechos, la conducta criminal real del primero constituye una base suficiente para juzgarlo y tratarlo desde el punto de vista de los juicios morales a nuestro

${ }^{13}$ Posiblemente, el libertarista sospechará que esta manera de poner las cosas presupone el determinismo. Para no prejuzgar esta cuestión, la expresión anterior, así como otras del mismo tipo que surjan más adelante deberían entenderse como si simplemente elidieran el adverbio "probablemente": lo que probablemente habría hecho si hubiera tenido la ocasión. Evito introducir el término cada vez.

${ }^{14}$ Como es sabido, el ejemplo procede de Nagel 1979. 
alcance, no digamos desde el punto de vista legal, como culpable; con respecto al segundo, no poseemos la misma evidencia para considerarlo igualmente culpable.

Cabe señalar que esta estrategia renuncia ya a la acción misma, y decisión real, del agente como locus de la responsabilidad, y lo sitúa en un elemento previo; en particular, en aquello por lo cual el agente habría actuado de una determinada manera si hubiese tenido la ocasión. Hay algo en Adolf en virtud de lo cual, si hubiese estado en las mismas circunstancias que Rudolf, habría actuado libremente del mismo modo. Para Richards no hay duda de que el locus de la evaluación lo constituyen las disposiciones estables o carácter del agente, con independencia de su realización (puntual) en casos particulares. Ésta es su versión de AE, referida a la suerte circunstancial:

El punto central de mi argumento será que si el agente potencial es tan parecido al real [actual] como estamos imaginando, entonces habrá alguna cosa más en su conducta que demandará la misma respuesta. Si esto es así, su suerte para llevar a cabo un hecho particular no afectará el trato que merece. Merecerá la misma clase de estímulo o recondicionamiento, pero lo merecerá por una realización diferente de un carácter igualmente virtuoso o vicioso. Su suerte no afectará, así, lo que merece, sino el momento en el que lo merece y, de nuevo, la claridad con la que puede verse que lo merece. (Richards 1986, p. 174)

Hay un sentido en que esto se sigue de casos cotidianos en los que juzgamos a alguien en virtud de que parece razonable pensar qué haría o habría hecho, si tuviese o hubiese tenido la oportunidad de hacerlo. Piénsese en esa persona que sólo te ayuda porque ve que puede obtener la aprobación de otras personas, pero que sospechas que si no fuera por esto no te haría ni caso; o en ese alumno que te saluda tan afablemente, pero sólo porque cree que es una manera de mejorar su nota. Si estos casos cotidianos pueden generalizarse, el resultado sería el vindicado por Richards, de que vinculamos nuestro juicio de alguien no con lo que ha hecho, sino con aquello que es plausible pensar que habría hecho si hubiese tenido la ocasión. ${ }^{15}$

Sin embargo, hemos de distinguir de nuevo la mera extensión contrafáctica de $\mathrm{AE}$, el núcleo de la propuesta, de ulteriores compromisos acerca del locus de la atribución de responsabilidad moral. Vemos que Richards se compromete con la idea de que el merecimiento verdadero de un sujeto está en función de su carácter. Pero

${ }^{15}$ Véase Richards 1986, pp. 173-174. 
este compromiso podría ser un impedimento a la hora de extenderlo a los tipos antecedentes de suerte moral, en los que precisamente está en juego el propio control del agente sobre el carácter que de hecho tiene. Otro impedimento en la misma dirección (que también constituye un desarrollo particular de la posición y no su núcleo) es la matización de "lo que es plausible pensar que habría hecho", esto es, el compromiso con el modificador "plausible". Claramente, conforme retrocedamos en la consideración de los factores de suerte antecedente más nos separaremos de las condiciones reales y actuales, con lo que este "plausible" se volverá progresivamente menos razonable o inteligible.

En todo caso, el principio puede extenderse (dejando de lado el "plausible") hasta abarcar la suerte antecedente, del siguiente modo: un agente es moralmente responsable en la medida en que éste habría realizado libremente la misma acción (o habría decidido libremente realizar la misma acción) que su hipotético par, si hubiese tenido la misma constitución y el mismo desarrollo y experiencias formativas - o la combinación de constitución más experiencia hubiese dado como resultado global la misma clase de persona-.

Pero podemos también prescindir de la idea de que el locus de la responsabilidad moral es el carácter o la predisposición a tener o desarrollar cierto carácter (que produciría ciertas disposiciones a decidir y actuar de cierta manera) en ciertas circunstancias, que (en algún sentido) el agente de hecho posee. La estrategia alternativa queda claramente ilustrada en el siguiente esquema de Michael J. Zimmerman, que radicaliza la idea de que el merecimiento último reside en lo que el agente habría hecho. Dado el principio de control,

Si (i) P tomó la decisión $d$ en la que creyó que era la situación $s$,

(ii) $\mathrm{P}^{*}$ habría tomado la decisión $d$ si hubiera estado en una situación que creyese que era $s, \mathrm{y}$

(iii) que el hecho de que $\mathrm{P}^{*}$ estuviera en una situación que creía que era $s$ no era algo que estuviera bajo su control $[\ldots]$,

entonces, sea cual sea el crédito o descrédito moral que le cabe a $\mathrm{P}$ por tomar la decisión $d$ le cabe también a $\mathrm{P}^{*}$. (Zimmerman 1987, p. 381) ${ }^{16}$

\footnotetext{
${ }^{16}$ He suprimido la referencia a "control restringido" (en contraposición a "control irrestricto") por no ser relevante aquí. Para la distinción, véase Zimmerman 1987, p. 376.
} 
El resultado es que $\mathrm{P}$ y $\mathrm{P}^{*}$ son igualmente elogiables o censurables. La cuenta de crédito moral de ambos, usando la imagen del mismo Zimmerman, se verá igualmente afectada, para bien o para mal, pues hay algo en ambos que los hace igualmente responsables. Cabe notar que, en este punto, Zimmerman se ha deshecho ya de AE (aunque podría seguir usándolo como explicación de nuestras prácticas de hecho) y concibe su posición como la "conclusión lógica" de la aplicación del principio de control hasta sus últimas consecuencias, sin la interferencia de ninguna otra consideración. ${ }^{17}$

Pero ese algo en virtud de lo que ambos son igualmente responsables no está ya claro ni siquiera qué pueda ser. ${ }^{18}$ En todo caso, se tratará de algo que el sujeto posee, aunque sea sólo potencialmente. $\mathrm{Y}$ no puede ser ni su voluntad o intenciones reales actuales ni su carácter tal y como está actualmente formado, o la predisposición a su formación dadas ciertas circunstancias, sino un mero hecho contrafáctico acerca de, o bien, cómo podrían ser su voluntad e intenciones, o su carácter, o bien, meramente acerca de cómo decidiría en la situación $s$. Pero este retroceso en los antecedentes de la conducta y el carácter (o configuración actual) del agente en cuestión implicará también plantear nuevas distinciones, como trataré de mostrar, entre tipos de merecimiento (verdadero).

\section{La estrategia moderada y la estrategia radical}

Tenemos ya datos suficientes para proponer una distinción entre dos grandes estrategias, bien diferenciadas, dentro del proyecto general de negar la existencia de la suerte moral. Son las que llamaré estrategia moderada y estrategia radical. Por supuesto, ambas estrategias parten de la defensa del principio de control (PC), pero lo hacen de modos distintos y adquiriendo unos compromisos positivos también divergentes.

En primer lugar, la estrategia moderada (EM) se caracteriza por combinar PC con la explicación y justificación de nuestras prácticas reales. Para su explicación, AE es una herramienta fundamental, mientras que la tesis conservadora desempeña las tareas justificativas.

${ }^{17}$ Véase Zimmerman 2002, p. 559.

${ }^{18}$ Para Zimmerman, el juicio de responsabilidad moral no puede estar en función del carácter del agente, pues para ello ya están los juicios aretaicos. Estos últimos, que se refieren al carácter, están necesariamente influidos por la suerte. Son los primeros, función del yo del agente, los que, libres de suerte, establecen el merecimiento verdadero del agente. Esta posición parece ser la más próxima a Kant, para quien es la mera buena voluntad la que marca el merecimiento verdadero o valía moral, con independencia de todo factor de tipo psicológico. 
Precisamente, la motivación de esta última es tratar de responder de un modo no revisionista a la cuestión de cómo debemos juzgar o qué debemos pensar acerca de nuestros juicios cotidianos, que aparentemente no respetan PC. Por otro lado, cuando PC y AE se extienden contrafácticamente, esta estrategia se compromete con la modificación de "plausible" del siguiente modo: juzgamos por cómo es plausible para nosotros pensar ${ }^{19}$ que el agente habría actuado si hubiera tenido la oportunidad. Finalmente, EM se compromete con que el locus del juicio es el carácter, disposiciones o intenciones que el agente de hecho tiene, origen de sus acciones. En síntesis, esta posición se basa en la idea de que si bien el principio de control es irrenunciable, no por ello nuestros juicios cotidianos han de ser radicalmente revisados - para éstos, lo mejor que tenemos es la evidencia disponible-.${ }^{20}$ En todo caso, la estrategia se aplica en principio sólo a la suerte resultante y a cierto tipo de suerte circunstancial, y calla en relación con los otros tipos de suerte moral. ${ }^{21}$

Pero estos compromisos adicionales que estamos considerando no son necesarios para la defensa del principio de control, pues cabe la opción de perseguir todas "las implicaciones de la negación de la relevancia de la suerte para la responsabilidad moral" hasta su "conclusión lógica". ${ }^{22}$ Así, la estrategia radical (ER) es una alternativa esencialmente revisionista. Si el principio de control, irrenunciable, no se aplica correctamente en nuestros juicios cotidianos - como parece que, de hecho, no lo es-, éstos resultan incorrectos y deben revisarse. En particular, se trata de una teoría del error: no es que nuestros juicios morales cotidianos no se refieran al merecimiento último de los agentes juzgados (o sólo lo hagan imperfectamente, como defiende EM), sino que pretenden referirse a él, pero sistemáticamente fallan.

${ }^{19}$ Véase Richards 1986, pp. 173-174.

${ }^{20}$ Dentro de EM se dan también variaciones: parece que en la versión de la distinción entre juicios legales o pragmáticos y juicios morales, o entre actos de censura y juicios de culpabilidad moral, sí que es factible un tipo de juicio referido a la culpabilidad o el merecimiento verdadero. Sin embargo, esto sólo sería posible en relación con los casos de suerte resultante. Aplicada a otros casos de suerte moral, esta opción se volvería revisionista.

${ }^{21}$ Cabe concebir EM como una estrategia argumentativa general en la que tendrían cabida los argumentos de todos aquellos teóricos que tratan de rechazar la suerte moral y que no están dispuestos a dar el paso hacia la posición revisionista radical que se detalla a continuación.

${ }^{22}$ Zimmerman 2002, p. 556. Los principales valedores de esta estrategia son Zimmerman 1987 y 2002, y Greco 1995. 
Además, ER está preparada para ir más allá de la mera aplicabilidad a la suerte resultante y circunstancial de EM y puede extenderse a la suerte antecedente; pues puede aceptar que las intenciones, la voluntad, el carácter y las mismas disposiciones que el agente de hecho se forma o tiene dependan, por lo menos parcialmente, de factores que están más allá del control del agente. Por ello fundamenta el merecimiento verdadero en las disposiciones que el agente habría podido tener dada su historia contrafáctica posible, esto es, las disposiciones que habría tenido si su historia fáctica hubiese sido otra, de entre el conjunto de historias posibles para su vida. (Explicaré esto con más detenimiento.) Con esto se desentiende de los otros dos compromisos adicionales que limitaban la extensión de EM: que el carácter o las intenciones actuales del agente constituyan el locus para su evaluación moral última, así como la restricción a lo "plausible". En resumen, ER es una estrategia más ambiciosa y comprehensiva que EM, pero, como es obvio, a costa de perder en razonabilidad o intuitividad y en aplicabilidad.

Distinguidas estas dos estrategias, a continuación replicaré a cada una de ellas. Consideraré más brevemente la estrategia moderada, respecto de la cual parece más fácil mostrar que es insuficiente como argumento global, pues falla irremediablemente en cuanto se intenta aplicar a la suerte antecedente (suerte formativa y constitutiva). Rechazada esta estrategia, pasaré a considerar la estrategia radical. Respecto de ella trataré de mostrar que, si bien su extensión a tipos antecedentes de suerte moral no es en principio lógicamente problemática, sí lo es llevarla hasta sus últimas consecuencias. ER resultará finalmente inaplicable y, lo que es más definitivo, incoherente. Si ni EM ni ER funcionan, y ambas agotan las posibilidades de maniobra del argumento global, entonces éste habrá sido refutado — siempre, como respuesta global-.

\section{La insuficiencia de EM}

La estrategia moderada se centra en distinguir el merecimiento verdadero del juicio que estamos justificados a proferir dada la evidencia disponible $(\mathrm{AE}) \mathrm{o}$, en otras variaciones, dadas las condiciones de los juicios legales o pragmáticos, o de los actos abiertos de censura. En todo caso, su mayor problema no es la distinción misma, sino la imposibilidad de extenderla más allá de la suerte resultante y circunstancial, dado su carácter esencialmente moderado. Por definición, ir más allá de ciertas consideraciones plausibles haría que perdiese su carácter intuitivo, que es el que le da ventaja sobre ER. 
Consideremos el caso de dos personas que comparten el propósito de asesinar a alguien, y que de hecho lo intentan, pero sólo una lo consigue. Llamemos Alonso al que lo consigue y Alfonso al asesino frustrado. Convengamos en que ambos estaban igualmente convencidos de sus intenciones y en que ambos han hecho todo lo que se hallaba en sus manos para llevarlas a término; para llegar a matar a Lola el día D. Pero resulta que cuando Alfonso se disponía a disparar a la que iba a ser su víctima, Lola entró en una tienda repleta de gente, y así Alfonso perdió su oportunidad y su plan se vio frustrado. Alonso tuvo más suerte (o menos) y pudo acabar con la vida de Lola, tal y como lo había planeado. Pues bien, si aplicamos EM a este caso, tendremos que el merecimiento (culpabilidad) de ambos es el mismo, dado que sus disposiciones y carácter son iguales en lo relevante; si bien la falta de evidencia puede llevarnos a juzgar más negativamente a Alonso, o a censurarlo de una manera más abierta, o a castigarlo legalmente con mayor rigor (homicidio o asesinato contra homicidio frustrado). Parece que la apelación a nuestras intuiciones más kantianas surte aquí su efecto. ${ }^{23}$

Pero extendamos el caso añadiendo una tercera persona o contraparte, Alfredo, que es igual en lo relevante a Alonso y Alfonso, pero que fue encarcelado (por un robo de poca monta) unos días antes del día D. En este caso, Lola se vuelve a salvar, ahora porque Alfredo no pudo acudir al lugar donde cometería el asesinato. Pero según EM, Alfredo es igual de culpable que Alonso y Alfonso, pues su intención era ir a acabar con la vida de Lola el día D. Los tres son igual de culpables a pesar de que lo de Alonso es un homicidio; lo de Alfonso, un homicidio frustrado y lo de Alfredo, no sé... ¿un propósito de homicidio? - pues aún no había conseguido la pistola, ni tampoco había pensado dónde ni cuándo dispararle, etcétera-. Pero podemos todavía añadir una cuarta persona, Alberto, para el que, aunque todo apuntaba a que se convertiría en un exitoso sicario, un accidente de coche, huyendo de la policía, lo apartó de la que pensaba iba a ser una muy lucrativa carrera. Alberto ya había sido contratado para acabar con la vida de Lola antes de sufrir el accidente y, por lo tanto, era parte de sus planes inmediatos disparar a Lola el día D. Según EM - o, estrictamente, según el principio de control—, Alberto es igual de culpable que Alfredo, Alonso y Alfonso. Usando una distinción

${ }^{23}$ Con ligeras variaciones, este caso es representativo tanto de la suerte resultante como de casos de suerte circunstancial que se asemejan profundamente a los de suerte resultante. En concreto, tal y como se ha descrito, es un caso de suerte circunstancial. 
de Zimmerman, podemos decir que su grado de responsabilidad será el mismo, aunque unos sean responsables por más cosas que otros. Es importante recalcar que la distinción entre grado y alcance no puede implicar la existencia de dos tipos distintos de juicios de responsabilidad moral igualmente fundamentales; sino que "[e]l grado de la responsabilidad lo es todo [y] el alcance no cuenta para nada en cuanto a la evaluación moral de los agentes", para que el argumento pueda funcionar. ${ }^{24}$

Sin embargo, parece que EM ya no puede hacerse cargo de este tipo de casos, dado que para el veredicto de la igual culpabilidad de todos los agentes ya no puede apelar meramente al carácter o disposiciones actuales; a la vez que el abandono progresivo de la historia real del agente hace que el compromiso con lo "plausible" se vaya debilitando paulatinamente. Nuestras intuiciones para con el caso se vuelven cada vez menos inmediatas, y se hace necesario algún tipo de revisión respecto de nuestras prácticas de juicio. Por ello, si la extensión de EM a casos progresivamente más antecedentes de suerte moral resulta cada vez más difícil, EM se torna insuficiente como argumento global. Cabe concluir, en consecuencia, que EM resulta ser inviable como argumento global, en tanto que no puede rechazar los tipos antecedentes de suerte moral. Sin embargo, el relevo lo tomará aquí sin problemas ER, cuyo único compromiso es el principio de control.

Debo aclarar que, aunque EM fracase como caso global, ello no impide que pueda resultar adecuado como argumento particular contra la suerte resultante y algunas formas de suerte circunstancial, formando parte de estrategias mixtas (que combinan diferentes argumentos para diferentes tipos de suerte moral) o híbridas (que aceptan ciertos tipos de suerte moral y rechazan otros). Por otro lado, eliminar la posibilidad de que estrategias de este tipo funcionen, lo cual requeriría una evaluación más detenida de los méritos específicos de EM para contrarrestar la suerte resultante y la suerte circunstancial, excede las pretensiones de mi argumento actual, además de los límites de espacio de este artículo. ${ }^{25}$

${ }^{24}$ Zimmerman 2002, p. 568; véase también Zimmerman 1987, pp. 383-384. En concreto, el alcance sólo será relevante para la determinación de los juicios de tipo deóntico (o también aretaico) que son ajenos al merecimiento último del agente.

${ }^{25}$ En Rosell (en prensa) defiendo, en particular, la suerte moral resultante contra el que llamo primado de la voluntad. Véase Rosell 2009 para un antecedente de los argumentos que trato de defender en ese artículo y en el presente, además de otras muchas cuestiones relacionadas con el tema de la suerte moral. 


\section{Los problemas de aplicación de ER}

El rechazo global de la suerte moral depende crucialmente de mostrar (i) que hay un tipo de evaluación moral privilegiado (fundamental), y (ii) que éste está libre de la suerte. Este tipo de evaluación moral fundamental reflejaría el merecimiento verdadero incondicionado del agente, que necesita ser caracterizado como independiente de la acción y decisión de actuar reales, e incluso independiente de las disposiciones y voluntad actuales del agente. Una objeción que puede resultar fatal para esta estrategia es que, de hecho, no exista un único tipo privilegiado de evaluación moral. Pero no desarrollaré esta objeción aquí, sino que, por mor del argumento, asumiré que lo hay, que hay un tipo de evaluación moral que es el privilegiado, y que está en función del merecimiento verdadero del agente, y persiguiendo esta idea trataré de concluir que, llevada a sus últimas consecuencias, resulta incoherente. En su conjunto, mi argumento funciona como una reducción al absurdo del siguiente modo:

1. Hay un tipo de evaluación (moral) que está completamente libre de suerte.

2. El tipo de evaluación libre de suerte es función del merecimiento verdadero o último de la persona evaluada (condición necesaria).

3. El merecimiento verdadero puede ser condicionado o incondicionado.

4. Un merecimiento verdadero condicionado es insuficiente para nuestro propósito (pues la suerte no sería completamente excluida).

5. Pero la idea de un merecimiento verdadero incondicionado es ininteligible.

6. Por lo tanto, no hay una noción de merecimiento verdadero que pueda desempeñar la función requerida.

7. Por lo tanto, no hay un tipo de evaluación moral completamente libre de suerte.

Creo que no se discutirá 1 a 4 . Quien dude de 4, debe recordar que estamos buscando aquí un tipo de evaluación moral libre de la suerte en todos sus tipos. Además, 4 ha quedado establecido por la discusión anterior de EM. En lo que sigue, me centraré en 5, 
esto es, en la idea de un merecimiento verdadero incondicionado, pues su posibilidad es crucial para el argumento contra la suerte moral. Mi rechazo de 5 se deberá a dos razones. La primera, más débil, responde a su inaplicabilidad. Reconozco que algunos teóricos pueden considerarse inmunes a esta primera objeción; para ellos guardo la segunda: la naturaleza incoherente de la noción misma. De aquí, se seguirán trivialmente 6 y 7 .

Veíamos que EM fracasaba cuando los escenarios por evaluar se alejaban en exceso del escenario real. Sin embargo, si estamos dispuestos a llevar la prevalencia del principio de control hasta sus últimas consecuencias, abandonando los compromisos de tipo conservador, no estrictamente necesarios - con lo intuitivo y plausible, con un elemento real en el agente que constituya el locus del juicio-, lo esencial es que el elemento de contingencia introducido por lo que de hecho somos responsables quede excluido.

Esta estrategia se apoya irrestrictamente en la idea de que el agente es responsable de aquello que habría decidido hacer si hubiese tenido la ocasión. Esto es, construyendo sobre el caso anterior de los asesinos, imaginemos que existe un tal Alonso*, contraparte de Alonso, pero que un día en su tierna infancia fue raptado, retenido y violado por un pederasta. Este hecho habría de marcar el resto de su vida. El que iba a ser un chico extrovertido, bravucón, con carácter, aficionado a vagar por los barrios bajos, a trapichear, con facilidad para meterse en líos y para conocer a tipos duros, etc., que finalmente asesinaría a Lola, se convirtió en un niño muy introvertido, apagado, incapaz de meterse con nadie, temeroso de andar dos bloques más allá de su casa. ${ }^{26}$ Pues bien, para ER, si la diferencia entre ambos se debe exclusiva o principalmente a este hecho (o lo que es lo mismo, no depende del control de Alonso*) - y podemos estipular que si este hecho no hubiese ocurrido su desarrollo personal no habría divergido del de Alonso, salvo por otros posibles sucesos también fuera de su control-, entonces ambos son igualmente responsables o culpables. En realidad, Alonso* no puede ser responsable del asesinato real de Lola, pues no la ha asesinado; sólo podría ser responsable sin más, o de un modo meramente contrafáctico, dado que la habría asesinado de no ser por aquel incidente. La idea es que uno puede ser responsable tout court incluso aunque no sea responsable de nada. Aunque no exista nada de lo que Alonso* sea responsable de hecho y

\footnotetext{
${ }^{26}$ Alonso* está inspirado en el personaje de Dave Boyle, de la novela Mystic River de Dennis Lehane (2001), fantásticamente interpretado por Tim Robbins en la película homónima dirigida por Clint Eastwood en 2005.
} 
en particular (como el simpatizante nazi Adolf, quien, a diferencia de Rudolf, no se vio realmente envuelto en ningún crimen); sin embargo, podemos y debemos considerarlo responsable en el mismo grado que a Alonso, pues también habría elegido libremente cometer el asesinato. ${ }^{27}$

Así, ER se ve obligada a multiplicar las distinciones. Cuando nos ocupábamos de José y Josué, veíamos que pese a tener historias morales distintas (uno atropelló a alguien y el otro no), para el adversario de la suerte moral ambos tenían el mismo merecimiento verdadero, sobre la base de su misma voluntad (intenciones, carácter, etc.); con lo que teníamos una distinción entre el juicio basado en el mero expediente moral real del agente, o historia de su conducta moral efectiva (con sus consecuencias efectivas), y su merecimiento verdadero. Pero, para seguir en esta dirección, ER necesita añadir una nueva distinción, entre este tipo de merecimiento, que va ligado a aquellas disposiciones que uno tiene dada su historia fáctica o real — que podemos llamar merecimiento verdadero fáctico-, y un tipo de merecimiento aún más fundamental, que dependerá de un conjunto más amplio de disposiciones posibles, que incluyen todas las historias contrafácticas posibles de la vida del agente. Llamemos a esto último merecimiento verdadero esencial. ${ }^{28}$

Esta noción, surgida de una aspiración legítima a separar el núcleo duro moral de una persona - lo que se refiere estrictamente a la persona misma - del conjunto de factores (de origen especialmente externo, pero también interno) que contingentemente lo envuelven, se ha ido radicalizando en virtud del anhelo (digamos que kantiano) de que lo que soy más fundamentalmente, y lo que exclusivamente debe ser juzgado, debe estar más allá de la suerte. ${ }^{29} \mathrm{El}$ merecimiento verdadero esencial, reflejo de la idea de responsabilidad moral última, sería ya el tipo de evaluación fundamental e incondicionado que se busca, necesario para librarnos por completo de la suerte. En contraste con los tipos de merecimiento y responsabilidad anteriores, de naturaleza fáctica, o parcialmente fáctica, se caracterizaría por ser perfectamente racional e "imputar una responsabilidad absoluta y

${ }^{27}$ Zimmerman (2002, pp. 564-565 y pp. 568-571) sobre la noción de responsabilidad tout court, o "sin más".

${ }^{28}$ Para una explícita defensa de este movimiento, véase Greco 1995. En sus términos, esta nueva distinción sería entre la "valía moral fáctica" y la "valía moral esencial" - que sigue a la distinción previa entre dos clases de juicios de responsabilidad moral: el que evalúa el expediente moral (juicio de responsabilidad moral propiamente dicho) y el que evalúa la valía moral o merecimiento último-.

${ }^{29}$ Cfr. Williams 1981, p. 38. 
por completo dentro del poder del agente", (Feinberg 1970, p. 344), expresada en juicios "absolutos" e intemporales — en cuanto independientes de todo propósito y con una finalidad última-.

Volviendo al caso que estamos considerando, el merecimiento (verdadero esencial) de Alonso y Alonso* será el mismo, en la medida en que debe basarse en las disposiciones que el agente habría podido tener, dadas las historias contrafácticas posibles de su vida $-\mathrm{y}$ esto aunque, de hecho, Alonso* haya acabado convirtiéndose en una persona modélica a raíz de aquel incidente- Lo que cuenta, para el defensor a ultranza del principio de control, serán las disposiciones que el agente habría tenido si su historia fáctica - la historia que de hecho ha tenido y que depende de infinitos sucesos que escapan a su control- hubiese sido otra, de entre el conjunto de historias posibles para su vida y que no han ocurrido de hecho. No cabe duda de que este movimiento, característico de ER, la convierte en una estrategia mucho más ambiciosa que EM, pero lo hace a un precio muy alto: la necesidad de abandonar la idea de que el carácter, las intenciones o las decisiones reales del agente constituyen el locus para su evaluación moral última, así como la armonía con nuestras intuiciones de sentido común (con lo "plausible").

Sin embargo, también podría suceder que el hecho de que Alonso acabase siendo un asesino, o alguien con la disposición de asesinar a un semejante, hubiese dependido de hechos anteriores en su vida, ajenos a su control. Supongamos que sus padres lo abandonaron de muy pequeño, que vivió en un ambiente muy degradado, etc., circunstancias sin las cuales muy probablemente no hubiese llegado a ese extremo. Si esto es así, el merecimiento último auténtico de Alonso no es el mismo que el de Alonso*: se trata ahora de otro mucho más positivo. Tendríamos como resultado que una persona modélica, además víctima de tan cruel abuso sexual en su infancia, merecería un desprecio moral mucho mayor que el sanguinario asesino de Lola, lo cual ya empieza a ser realmente difícil de digerir.

Reconozco que esta réplica puede parecer un tanto demagógica, pero es fiel al fondo de la propuesta que discuto. En todo caso, quiero proponer dos objeciones ulteriores, que inciden principalmente en la inaplicabilidad de esta propuesta. En primer lugar, la atacaré sobre la base de las dudas escépticas que parece suscitar la separación radical del merecimiento verdadero y el historial o expediente moral efectivo del agente. En segundo lugar, defenderé la implausibilidad e imposibilidad real de llevar a cabo el revisionismo radical (irrealista) que se sigue de sus conclusiones, además de sus consecuencias moralmente perniciosas. 
Empecemos con la primera objeción. Hemos llegado al punto en que había dos tipos principales de evaluación moral en juego: la que evalúa el historial moral del agente y la que evalúa su merecimiento verdadero - como función de lo que el agente habría hecho, dado el conjunto de sus historias contrafácticas posibles-. Pero, ¿qué hay del décalage entre las bases para uno y otro tipo de evaluación? A mi juicio, esta posición crea una separación preocupante (quizá, insalvable) entre historia real y merecimiento que, por lo pronto, es claramente indeseable. No obstante, el adversario de la suerte moral puede reconocer que es realmente difícil emitir un juicio sobre el merecimiento verdadero (esencial), pero que esto no implica un escepticismo radical acerca del merecimiento verdadero. Juicios limitados acerca del merecimiento pueden ser razonables, aunque debamos ser muy cautos al emitirlos. ${ }^{30}$ Además, podría defenderse que esta posición produce la siguiente consecuencia positiva: un razonable escepticismo acerca del merecimiento último minaría nuestra severidad a la hora de censurar a aquellos que se han visto inmersos en situaciones menos afortunadas que nosotros. ${ }^{31}$ Pero precisamente éste es un resultado decididamente vindicado por los defensores de la suerte moral: una consecuencia que se sigue de reconocer que la suerte se introduce en cómo juzgamos y somos juzgados moralmente es que no debemos ser especialmente severos con quienes se han visto sometidos a circunstancias menos afortunadas - sin que por esto dejen de ser responsables por como de hecho han actuado- . Y todo ello sin necesidad de postular una entidad tan oscura como la de merecimiento verdadero, en el sentido en que se ha caracterizado.

Otra réplica disponible para el adversario de la suerte moral sería ésta: el historial moral de una persona es un signo de su merecimiento verdadero, pues las circunstancias en que una persona de hecho elige y actúa son un subconjunto del espectro total de circunstancias en que la persona habría elegido y actuado; de este modo "el historial moral de una persona provee una ventana a la valía moral de la persona" (Greco 1995, p. 93)..$^{32}$ Sin embargo, esta tesis no parece ser del todo accesible a ER - de hecho, tal vez sólo sea accesible al defensor de EM que reconoce en las consecuencias, acciones y disposiciones efectivas un indicador directo del merecimiento- - La idea es que una vez que se ha renunciado a una concepción, digamos, falible del juicio de responsabilidad moral y se adopta una perspectiva

\footnotetext{
${ }^{30}$ Véanse Richards 1986, Greco 1995, y Rosebury 1995.

${ }^{31}$ Greco 1995, pp. 93-94.

${ }^{32}$ Cfr. Richards 1986.
} 
infalibilista u omnisciente, el criterio para establecer que algo cuenta para determinar el merecimiento verdadero es tan exigente, que difícilmente podrá satisfacerse. Quedarse en un escepticismo moderado o afirmar que la historia de alguien nos suministra una ventana a su merecimiento verdadero es, bajo esas condiciones, mero pensamiento desiderativo. De nuevo, una vez que disociamos por principio el merecimiento verdadero del historial moral real, la conexión entre ambos se rompe irremediablemente.

Quizá, llegados a este punto, la respuesta más coherente del defensor de ER fuese decir que juzgar a los demás (y a uno mismo) es, en último término, imposible para nosotros, seres cognitivamente limitados a los que les es inaccesible una gran cantidad de información contrafáctica, necesaria para conocer el merecimiento verdadero de alguien. Podemos llamar a esto escepticismo à la Dostoievski: la evidencia para emitir juicios de merecimiento con la que podemos contar es necesariamente insuficiente; sólo un ser omnisciente estaría en condiciones de poder emitir tales juicios justificadamente. ${ }^{33}$ A esto se podría replicar: ¿entonces, cuál es la función de la idea misma de merecimiento verdadero? Parece que la única respuesta que queda disponible ya es precisamente la típicamente kantiana: constituye un ideal regulativo, un ideal que regula nuestra consideración moral de las personas. Este movimiento es parcialmente ajeno a los principales defensores de ER, pero supone aún una salida que quedará también desacreditada si mis argumentos en el siguiente apartado son correctos.

Pero hay aún otra objeción previa significativa, en relación con el problema de la aplicabilidad, para la posición que venimos considerando: la irrealidad de sus prescripciones. El mismo Zimmerman, defendiendo esta posición, llega a la convicción — que, de hecho, se sigue de su idea de responsabilidad tout court - de que todos aquellos que, en ciertas circunstancias, hubiesen actuado libremente tal como actuó, por ejemplo, el colaborador nazi, son ya tan culpables como éste. Esto se aplica también a la laudabilidad.

\footnotetext{
${ }^{33}$ Cabe decir que el escepticismo sobre el juicio de responsabilidad moral es una posición distinta del escepticismo sobre la responsabilidad moral (como el de Spinoza o, más recientemente, Derk Pereboom o Galen Strawson). El primero no tiene por qué incluir al segundo. El escéptico sobre el juicio moral puede conceder que las condiciones para la responsabilidad moral pueden e incluso son satisfechas en el mundo real, pero que en ningún caso estamos justificados a juzgar que alguien es responsable de $x$, debido a nuestros límites cognitivos. Para una defensa reciente de una posición de este tipo, véase Rosen 2004.
} 
[D]ado que un número indefinido de contrafácticos acerca de lo que habríamos hecho si hubiésemos estado en una situación diferente pueden ser verdaderos al mismo tiempo, podemos ser moralmente responsables tout court - tanto positiva como negativamente - para un número indefinido de grados al mismo tiempo. (Zimmerman 2002, p. 570)

Se sigue sin dificultad que todos nosotros somos censurables (y elogiables) por una incontable cantidad de cosas de las que "ni nos imaginamos", (Zimmerman 1987, p. 226), dado que tenemos diferentes contrapartes que en situaciones posibles habrían actuado incorrectamente, y no está justificado un juicio diferente en virtud de consideraciones meramente fácticas. Pero, si esto es así, la mayoría de nuestros juicios cotidianos, si no todos, se volverían ilegítimos.

Desde luego, este resultado arroja importantes dudas sobre nuestras prácticas actuales. De hecho, Zimmerman responde con la prescripción de una revisión general de nuestras prácticas, que afectaría no sólo los juicios morales, sino también otras prácticas asociadas, como el castigo legal, ${ }^{34}$ aunque no propone cómo llevar a cabo efectivamente esta revisión generalizada. ¿Cómo podríamos revisar nuestros juicios morales de hecho en virtud de una multiplicidad de juicios esencialmente contrafácticos, esto es, en virtud de un número indefinido de contrafácticos verdaderos acerca del aspecto particular que se pretende juzgar? Si los múltiples juicios contrafácticos referidos a cada aspecto por el que se pretende juzgar a una persona, cuyo número es indefinido, han de ser igualmente tomados en consideración, se tornará imposible fijar un juicio determinado como el adecuado para cada sujeto y circunstancia. En consecuencia, ¿cómo revisar el castigo impuesto a alguien a la luz de este número indefinido de contrafácticos en torno al acto por el que fue castigado? ¿Cómo podríamos llegar, en estas condiciones, a un veredicto o resolución acerca de la pena impuesta?

Por otro lado, y ésta es la segunda cuestión, de esta propuesta parece seguirse que todos somos igualmente censurables y elogiables por todo. En otras palabras, las diferencias entre individuos en relación con los juicios de responsabilidad moral apropiados parecen disolverse, en virtud de la generalización universal de los juicios de responsabilidad moral, bien por incremento de la culpabilidad, bien por su mitigación. Este resultado supondría una forma de acabar con la misma idea de (juicios de) responsabilidad moral $-\mathrm{y}$, aplicado al castigo, el resultado sería que nadie debería ser castigado nunca,

${ }^{34}$ Veáse Zimmerman 2002, p. 571. 
o que todos merecemos serlo en la misma medida-. Zimmerman cree que puede resistir esta conclusión (2002, p. 571), pero todo dependerá de que pueda seguir manteniendo coherentemente ciertas diferencias entre individuos. Es lo que discutiré en la última sección. Pero, al margen de esto, la conclusión de esta sección es clara: la aplicación consecuente de este tipo puro de merecimiento generaría un revisionismo completamente impracticable. ${ }^{35}$

\section{7. "Merecimiento verdadero esencial"}

Bien, aun cuando la propuesta de ER sea completamente inútil como guía para nuestras atribuciones de responsabilidad moral cotidianas, podría de todos modos ser correcta en un plano ideal o conceptual. Pero no podrá serlo si la noción de merecimiento verdadero resulta completamente imposible de fijar o de dotar de contenido. Es lo que trataré de mostrar en esta sección.

Una cuestión preliminar. ER defiende ahora que la idea de merecimiento verdadero (esencial) es idealmente correcta. Esta salida tiene un problema obvio: la cuestión de la suerte moral se origina dentro de nuestras prácticas de evaluación moral cotidianas, y no en escenarios lógicamente posibles. Este fenómeno parece introducir problemas importantes en nuestras prácticas cotidianas, problemas que inciden en prácticas que funcionan como guías de nuestras relaciones interpersonales. Por ello, la solución de la cuestión en términos de condiciones ideales no hace más que cambiar de tema. En otras palabras, la solución a la cuestión acaba no refiriéndose en ningún extremo a las prácticas cotidianas, por lo que no parece que pueda ser muy prometedora en relación con el presente problema - lo será, en todo caso, con otro- - La objeción aquí es que esta posición parece haber dejado de lado la misma cuestión que estamos discutiendo. No obstante, mi adversario podría responder que si tenemos en cuenta que lo que está en duda es la difícil compatibilidad entre

\footnotetext{
${ }^{35}$ Por supuesto, existen también razones generales de tipo metateórico para oponerse a un revisionismo tan radical. En primer lugar, toda teoría revisionista parte con la desventaja de chocar con nuestras intuiciones preteóricas, más si se refiere a nuestras prácticas cotidianas, y más aún si pretende alterarlas radicalmente. La pervivencia de estas prácticas es un hecho que juega a su favor, por lo que es la propuesta de revisión radical la que debe mostrar que esta revisión es claramente necesaria, además de venir avalada por un plan de viabilidad. Nada de esto esbozan los defensores de ER. Por otro lado, una revisión radical que finalmente consiguiese hacerse efectiva podría también generar un desastre práctico, quizá irreversible, o dolorosamente reversible. Piénsese en ciertas ideologías basadas en una ingeniería social revisionista radical.
} 
un principio y unas prácticas, incidir sólo en las prácticas y negar la posibilidad misma de una solución en términos del principio puede constituir igualmente una petición de principio. Ante esta réplica, lo que requiere mi argumento es una razón de peso independiente que bloquee la vía de escape idealizadora o conceptualista. Por ello, trataré de mostrar ahora que la noción misma de merecimiento verdadero o último es finalmente incoherente o ininteligible.

Vimos que las acciones, en cuanto externas al agente y nunca libres de contingencias (esto es, la realización externa de las acciones), no podían ser el locus de la responsabilidad última o merecimiento verdadero. Sin embargo, el carácter, las intenciones o la voluntad reales tampoco podían ocupar su lugar. Ni siquiera sus disposiciones más estables resultaban satisfactorias, dado que estas disposiciones surgieron, en parte, por la intervención de la suerte. Y si la suerte reaparece en escena, seguimos sin resolver la cuestión; pues lo que estamos haciendo es meramente posponer su aparición, dado que, recuérdese, el merecimiento verdadero ha de ser incondicionado, es decir, no puede ser cosa de suerte en absoluto. El movimiento del adversario de la suerte moral era, pues, favorecer una distinción entre merecimiento verdadero fáctico y merecimiento verdadero esencial, y abandonar así la evaluación de las disposiciones reales del agente - su historia real, que incluye lo que el agente habría hecho dadas sus disposiciones reales - , para pasar a evaluar lo que el agente habría elegido y hecho libremente en una diversidad de situaciones posibles pertenecientes a una multitud de historias posibles de su vida. Era este último tipo de evaluación el que parecía evitar la suerte. Sin embargo, estas historias contrafácticas posibles son, para cada agente, innumerables - aunque posiblemente no infinitas - . Cada agente, a lo largo de su vida, afronta situaciones que lo van llevando a la realización de un historial moral determinado, de entre todos los posibles; a una formación y un desarrollo particulares de su carácter y disposiciones. Así, estos sucesos, que están fuera del control del agente - y que no tienen por qué determinarlo, sino que basta con la influencia que ejercen sobre él- apartan la historia real del agente del resto de historias posibles para su vida moral. Si queremos hacer más concreta esta imagen, creo que caben dos opciones: o bien hay una entre todas las historias morales posibles del agente que sería reflejo de su merecimiento verdadero, o bien su merecimiento verdadero es simplemente una afirmación en esencia contrafáctica. En todo caso, para que esta historia pudiese tener un final feliz - y esto es lo verdaderamente crucial- habría que hallar o determinar algún elemento en el agente (su verdadero yo moral, si se quiere) libre de toda influencia de la 
suerte, sobre el que hacer recaer, en último término, el merecimiento verdadero.

Pero el problema del retroceso progresivo en la determinación del merecimiento verdadero al que el negador se ha visto impelido, el cual comporta una reducción progresiva paralela de la identidad (real, pero también potencial) del agente, nos encamina hacia una de las alternativas siguientes, ninguna de las cuales es satisfactoria. Una alternativa es tratar de poner freno al retroceso progresivo apelando a una identidad esencial o propiedades esenciales del agente - esto es, aquellas propiedades que hacen que el agente sea quien es-. Además, sin propiedades esenciales sobre las cuales descansar, los contrafácticos se tornan falsos. Sin embargo, como Zimmerman reconoce, si tiene sentido hablar de las propiedades esenciales de alguien, entonces la suerte no es completamente eliminable. ${ }^{36}$ Pero, más allá de este comedido reconocimiento, la cuestión está en último término en que hacer descansar el merecimiento verdadero de un agente en sus propiedades esenciales supone, en realidad, decantarse por fundar el merecimiento verdadero de un agente meramente en su constitución original. Esto es, la evaluación de un contrafáctico como "Georg (probablemente) habría matado a Henrik si se le hubiera presentado la ocasión" dependería finalmente de la cualidad de la constitución (o verdadero yo) original de Georg, pues los consiguientes cambios reales en la cualidad de ésta dependerán siempre de circunstancias al margen de su control. Es decir, cualquier disposición, desarrollo caracterológico, intención, decisión o acción posterior dependerá parcialmente siempre de factores contingentes, que el agente no controla. Con lo que, en último término, su contribución estricta (al margen de la suerte) procedería - en la medida en que no sea fruto del azar o de determinaciones ajenas - de la cualidad de su constitución original (o propiedades esenciales); y esto supone sencillamente anular la posibilidad misma de que la persona pueda contribuir a su merecimiento verdadero con el ejercicio real de su agencia. ${ }^{37}$

\footnotetext{
${ }^{36}$ Zimmerman 2002, p. 575. Es importante hacer notar que la conclusión a la que Zimmerman (2002) pretende llegar es que lo que en último término importa con respecto a los juicios de responsabilidad moral no es si el agente podría haber actuado de tal modo, sino si lo habría hecho si las circunstancias hubiesen cooperado (p. 567). Si esto es así, "las cuestiones de si la responsabilidad moral requiere posibilidades alternativas y si tal responsabilidad requiere el indeterminismo causal resultan ser menos importantes de lo que tradicionalmente se ha creído" (p. 576). Pero si mi contraargumento es convincente, la razón aportada por Zimmerman para socavar estas cuestiones quedará desacreditada.

${ }^{37}$ Fundar el merecimiento de una persona en la constitución esencial parece ser
} 
La otra alternativa es simplemente reconocer que las "consecuencias últimas" de una defensa completamente consecuente de PC es la reducción final de la identidad moral del agente (de aquello que cuenta para determinar su merecimiento verdadero) a la nada. $\mathrm{O}$ a un mero yo sin propiedad alguna, ni física ni mental; un yo nouménico o trascendental, que esté más allá de cualquier cualidad del sujeto. ${ }^{38}$ Pero, en caso de que tal noción fuese realmente concebible, en la medida en que este yo no posea cualidades, no habrá nada sobre lo que basar su merecimiento; esto es, no habrá nada en virtud de lo cual sea posible juzgarlo. Asimismo, tampoco podremos salvaguardar diferencia alguna, no contingente, entre individuos. De este modo, llevada a sus últimas consecuencias, la negación de la suerte moral se torna en una posición sin sentido, pues finalmente no queda nada (no queda agente) sobre lo que basar el merecimiento verdadero.

Ambas alternativas resultan, pues, insostenibles. La última, porque hace desaparecer la idea misma de merecimiento y de responsabilidad moral asociada (esto es, para una noción de responsabilidad moral que se defina en términos de merecimiento verdadero); y la primera, simplemente porque aceptar la suerte constitutiva supone echar por la borda la motivación inicial por la que se aceptaba PC, pues si hay algo que el agente no puede controlar en absoluto, ésa es su constitución original. Basar a fin de cuentas el merecimiento moral de una persona meramente en su constitución original es renunciar por completo a PC. No se trata sólo de que finalmente se renuncia a llevar PC a sus últimas consecuencias, concediéndole un papel muy limitado a la suerte, sino que al final todo recae sobre la constitución original, que es algo que a cada cual le es simplemente dado.

Concluyo, con ello, que la noción de merecimiento verdadero - tal y como ha sido caracterizada - resulta incoherente, pues o bien i) se desvanece, al acabar dependiendo de un mero yo sin atributos, o bien ii) depende crucialmente de la constitución original del agente, lo cual escapa irremediablemente a su control y, por lo tanto, deja de ser un merecimiento incondicionado, como se exigía. Así, ER también fracasa como estrategia argumentativa general contra todo tipo de suerte moral, ya que depende de una noción incoherente.

una posición únicamente deseable para un calvinista extremo, que sólo parece tener sentido a partir del compromiso con la existencia de algo así como un alma que contiene en sí ya (¿todo?) el valor moral del individuo.

${ }^{38} \mathrm{La}$ posición de Kant parecer ser coherente a este respecto. No obstante, su metafísica está lejos de ser aceptable hoy en día. 


\section{Consideraciones finales y conclusión}

El propósito de este artículo ha sido confrontar los argumentos recientes contra la suerte moral. Por un lado, he tratado de reconstruir de la manera más convincente posible el argumento global contra la suerte moral, distinguiendo dos estrategias principales; y, por el otro, he dado razones para rechazar cada una de ellas. Un propósito fundamental de mi argumento ha sido desacreditar la noción de merecimiento verdadero, en el sentido fuerte de función estricta del control del agente (o estrictamente proporcional a dicho control), como medio necesario para impugnar la realidad del fenómeno de la suerte moral. Mi conclusión es que, llevada a sus últimas consecuencias, la idea termina siendo ininteligible. De este modo, en la medida en que necesariamente depende de esta noción, ningún argumento global podrá funcionar a fin de cuentas. ${ }^{39}$

El que era inicialmente un fin legítimo de nuestro juicio moral, a saber, aspirar a que las atribuciones de responsabilidad moral (en cuanto referidas al estatus moral de una persona) sean profundas, reflejen algo que "realmente pertenece a la persona", aislando los rasgos que más fielmente definen a la persona de los rasgos formativos y

${ }^{39}$ Así, la reducción al absurdo se completa con un argumento al que podríamos llamar trascendental: la noción de merecimiento verdadero, cuya incoherencia interna he tratado de mostrar, es un presupuesto indispensable para el rechazo total de la suerte moral.

En conjunto, el argumento que he presentado va en la dirección del de Nagel, pero se enfrenta directamente a los argumentos propuestos posteriormente como respuesta a Nagel (y a Williams). Por otro lado, mi argumento guarda cierto paralelismo con el desplegado por Michael Moore (1994), pero difiere en aspectos significativos, que lo hacen, a mi juicio, más modesto, pero más sólido. El de Moore es un argumento de todo o nada, según el cual, si hemos de ser responsables de algo, lo hemos de ser de todo aquello en lo que estamos agencialmente envueltos, incluidas las consecuencias reales de nuestros actos, pues no hay manera de establecer una distinción de principio entre distintos aspectos de nuestra agencia. Así, por un lado, este argumento depende del rechazo ad hoc del escepticismo con respecto a la responsabilidad moral. Por el contrario, el mío ataca primordialmente la noción de merecimiento verdadero - y toda noción de responsabilidad moral que se defina en términos de merecimiento verdadero - en su calidad de imprescindible para impedir por completo que la suerte se inmiscuya en el juicio moral que alguien merece. Por otro lado, a diferencia de Moore, no pretendo que de mi argumento se siga la vindicación de todas las formas de suerte moral. De hecho, me inclino a pensar que el argumento de Moore es víctima de una falacia de la pendiente resbaladiza, que sólo puede evitarse aceptando que del argumento no se sigue la vindicación de todos los tipos de suerte moral, sino solamente la imposibilidad de excluir por completo la suerte de nuestros juicios de responsabilidad moral. Pero, entonces, el argumento de Moore resulta fallido, pues su meta era defender, en particular, la suerte moral resultante. 
ambientales externos; si se pretende llevar al extremo, acaba convirtiéndose en una aspiración vana e incoherente. En otras palabras, una aspiración en principio intuitivamente legítima se ha vuelto manifiestamente ininteligible al hacerla absoluta. Por otro lado, una vez que nuestras intuiciones generales contra todo tipo de interferencia de la suerte en nuestros juicios morales quedan desacreditadas, empeñarse en negar la existencia de la suerte moral en ciertos tipos concretos pierde gran parte de su sentido. ${ }^{40,41}$

\section{BIBLIOGRAFÍA}

Bennett, J., 1995, The Act Itself, Clarendon Press, Oxford.

Davis, M., 1986, "Why Attempts Deserve Less Punishment than Completed Crimes", Law and Philosophy, vol. 5, pp. 1-32.

Enoch, D. y A. Marmor, 2007, "The Case against Moral Luck", Philosophy and Law, no. 26, pp. 405-436.

Feinberg, J., 1995, "Equal Punishment for Failed Attempts: Some Bad but Instructive Arguments against It", The Arizona Law Review, vol. 37, pp. 117-133.

— 1970, Doing and Deserving: Essays in the Theory of Responsibility, Princeton University Press, Princeton.

Hart, H.L.A., 1986, Punishment and Responsibility, Oxford University Press, Nueva York.

Greco, J., 1995, “A Second Paradox Concerning Responsibility and Luck”, Metaphilosophy, vol. 26, pp. 81-96.

Jensen, H., 1984, "Morality and Luck", Philosophy, vol. 59, pp. 323-330 (reimpreso en Statman 1993, pp. 131-140, a cuyas páginas corresponden las referencias).

${ }^{40} \mathrm{Si}$ bien es cierto, repito, que el argumento presentado no muestra que todos los tipos de suerte moral sean una realidad — véase la nota anterior- De hecho, puede haber buenas razones particulares para no aceptar un determinado tipo de suerte moral; lo que puede dar lugar a estrategias híbridas, como la de aquellos que sólo niegan la suerte moral resultante. No obstante, en otros lugares he tratado también de resistir estas estrategias híbridas; véase la nota 25.

${ }^{41}$ Este trabajo se encuadra en el proyecto de investigación "Alternativas, creencia y acción" (FFI2009-09686), financiado por el Ministerio de Ciencia y Tecnología del Gobierno de España y con los fondos FEDER de la Unión Europea. Debo mencionar también el Programa VALi+d de la Conselleria d'Educació de la Generalitat Valenciana, del que soy investigador posdoctoral. Son muchas las personas con las que he discutido las cuestiones tratadas en este trabajo durante los últimos años, de lo que, sin duda, me he beneficiado enormemente. Quiero destacar a Josep Corbí, George Couvalis, Carlos Moya, Dana Nelkin y Tobies Grimaltos, así como a los dos árbitros anónimos de esta revista. 
Latus, A., 2001, "Moral Luck", The Internet Encyclopedia of Philosophy, J. Feiser, ed., disponible en: < http://www.iep.utm.edu/m/moralluc.htm> [última consulta: 05/03/2012].

- , 2000, "Moral and Epistemic Luck", Journal of Philosophical Research, vol. 25, pp. 149-172.

Lehane, D., 2001, Mystic River, Harper Collins, Nueva York.

Levy, K., 2005, "The Solution to the Problem of Outcome Luck: Why Harm Is Just as Punishable as the Wrongful Action That It Causes", Law and Philosophy, vol. 24, pp. 263-303.

Lewis, D., 1989, "The Punishment That Leaves Something to Chance", Philosophy and Public Affairs, vol. 96, pp. 227-242.

Lucas, J.R., 1993, Responsibility, Clarendon Press, Oxford.

Moore, M., 1994, "The Independent Moral Significance of Wrongdoing", Journal of Contemporary Legal Issues, vol. 5, pp. 237-281 (reimpreso en Moore, Placing Blame: A Theory of the Criminal Law, Clarendon Press, Oxford, 1997, cap. 6).

Nagel, T., 1979, "Moral Luck", Mortal Questions, Cambridge University Press, Nueva York, pp. 24-39. [Versión en castellano: La muerte en cuestión, trad. Carlos Valdés, Fondo de Cultura Económica, México, 1981.]

Rescher, N., 1990, "Luck", American Philosophical Association Proceedings, vol. 64, no. 3, pp. 5-20 (versión revisada bajo el título "Moral Luck", en Statman 1993, pp. 141-166, a cuyas páginas corresponden las referencias).

Richards, N., 1986, "Luck and Desert", Mind, vol. 65, pp. 198-209 (reimpreso en Statman 1993, pp. 167-180, a cuyas páginas corresponden las referencias).

Rosebury, B., 1995, "Moral Responsibility and Moral Luck", Philosophical Review, vol. 104, pp. 499-524.

Rosen, G., 2004, "Scepticism about Moral Responsibility", Philosophical Perspectives, vol. 18, pp. 295-313.

Rosell, S., 2009, “Carácter, circunstancias y acción. El papel de la suerte en la determinación de la responsabilidad moral", tesis doctoral, Universitat de València, disponible en: < http://www.tesisenred.net/bitstream/handle/ 10803/10088/rosell.pdf> [última consulta: 22/03/2012].

—., 2006, "Nagel y Williams sobre la suerte moral", Revista de filosofía, vol. 31, no. 1, pp. 143-165.

—

Statman, D. (comp.), 1993, Moral Luck, State University of New York Press, Albany.

Sverdlik, S., 1988, "Crime and Moral Luck", American Philosophical Quarterly, vol. 25, pp. 79-86 (reimpreso en Statman 1993, pp. 180-194).

Thomson, J.J., 1989, "Morality and Bad Luck", Metaphilosophy, vol. 20, pp. 203-221 (reimpreso en Statman 1993, pp. 195-216, a cuyas páginas corresponden las referencias). 
Williams, B., 1981, "Moral Luck”, Moral Luck. Philosophical Papers 19731980, Cambridge University Press, Cambridge, pp. 20-39. [Versión en castellano: La fortuna moral. Ensayos filosóficos 1973-1980, trad. Susana Marín, Instituto de Investigaciones Filosóficas-UNAM, 1993.]

Wolf, S., 1990, “Asymmetrical Freedom”, Journal of Philosophy, vol. 77, pp. 157-166.

Zimmerman, M., 2002, "Taking Luck Seriously", Journal of Philosophy, vol. 99 , pp. $553-576$.

—_, 1987, "Luck and Moral Responsibility", Ethics, vol. 97, pp. 374386.

Recibido el 26 de febrero de 2011; revisado el 18 de septiembre de 2011; aceptado el 8 de febrero de 2012. 